\title{
Personality Traits and the Feeling of Loneliness of Post-Graduate University Students
}

\author{
Dr. Satyananda Panda ${ }^{1} *$
}

\section{ABSTRACT}

Loneliness as a psychological phenomenon is a state of mind rather than an objective condition. Individuals may feel lonely while totally surrounded by others or may be totally fine on their own. The purpose of this research was to examine personality traits and the feeling of loneliness of post-graduate university students. For this purpose, a non-clinical sample of 60 post-graduate students (30 male and 30 female) from various disciplines in the age group of 21 to 24 years were administered NEO Five-Factor Inventory-3 (NEO-FFI-3) and perceived loneliness scale. Correlation analysis showed that three Big Five personality dimensions which are openness, agreeableness and conscientiousness are negatively and moderately correlated with loneliness of post-graduate university students. However, significant differences were not found among male and female post-graduate university students on loneliness and Big Five personality dimensions. But since high level of mean scores of feeling of loneliness were found among both male and female post-graduate university students in this study, professionals need to pay attention to university students' psychosocial state.

Keywords: Loneliness, Personality, Agreeableness, Openness, Post-graduate students.

Loneliness as an important personality variable in current psychological literature is of particular interest to social psychologists. Probably most people experience painful feeling of isolation and loneliness at some point in their lives. Because life is filled with social transitions that disrupt personal relationships and set the stage for loneliness. Being unloved and lonely has been called "the greatest poverty". Perhaps for more people than we realize, the world is a lonely place. To date, the experts have not agreed upon definition of loneliness. There is, however, a general consensus among researchers about the inevitability of loneliness (Medora \& Woodward, 1986).

According to Peplau and Perlman (1982), "loneliness is the unpleasant experience that occurs when a person's network of social relations is deficient in some way". Loneliness has also been

\footnotetext{
${ }^{1}$ Assistant Professor, Department of Psychology, Sikkim University, Gangtok (Sikkim) - India.

*Responding Author

(C) 2016 I S Panda; licensee IJIP. This is an Open Access Research distributed under the terms of the Creative Commons Attribution License (http://creativecommons.org/licenses/by/2.0), which permits unrestricted use, distribution, and reproduction in any Medium, provided the original work is properly cited.
} 


\section{Personality Traits and the Feeling of Loneliness of Post-Graduate University Students}

defined as the inability to find meaning in one's life. Loneliness refers to an individual's subjective perception that he/she lacks close interpersonal relationships. An individual is lonely if he or she desires close interpersonal relationships but is unable to establish them.

Loneliness is a common, universal human experience with emotional, cognitive, motivational, and behavioural dimensions, and has various types and degrees. Weiss (1973) identified two types of loneliness, emotional loneliness and social loneliness; he suggested that the former results from the loss or lack of an intimate tie, whereas the latter results from the lack of a network of involvements with peers, neighbours, or friends.

In general, loneliness is a psychological mode caused by the weakness of personal communication and socialization skills (Arnett, 2007a). Loneliness is a complex set of feelings encompassing reactions to the absence of intimate and social needs. Although transient for some individuals, loneliness can be a chronic state for others. Chronic feelings of loneliness appear to have roots in childhood and early attachment processes. Chronically lonely individuals are more likely to be high in negative affectivity, act in a socially withdrawn fashion, lack trust in self and others, feel little control over success or failure, and generally are dissatisfied with their relationships compared to non-lonely individuals. Loneliness has also been associated with a variety of individual differences including depression, hostility, pessimism, social withdrawal, alienation, shyness, and low positive affect; loneliness is also a concomitant of more severe disorders, such as clinical depression, borderline personality, and schizophrenia.

\section{Personality and Loneliness}

Several personality factors have been linked to loneliness. Lonely people tend to be more introverted and shy, more self-conscious, and less assertive (Jones, Briggs \& Smith, 1986). Jones, Carpenter and Quitana (1985) in a study revealed that lonely people often have low selfesteem and in some cases, have poor social skills. Loneliness is also associated with anxiety and depression. A lonely individual experiences a feeling of profound sadness and the whole world becomes joyless and grey. Nothing seems worthwhile anymore; emptiness prevails, and only bad things are expected.

The Self-disclosures of those who are lonely tend to be inappropriate. They are too intimate with those of the same sex and too unrevealing to members of the opposite sex. Among the effects of those interpersonal deficits is the tendency to be cynical about other people, to feel pessimistic about life and to express an external locus of control (Jones, 1982). Their views of the opposite sex seem designed to maximise failure. Lonely individuals are less likely to believe in love as a basis for marriage and more likely to expect that their own marriage will end in divorce (Jones, Hansson, \& Smith, 1980).Several of these personality factors can be both a cause and consequence of loneliness. For example, people with low self-esteem may be less willing to take risks in social settings. This could make it harder for them to form friendships and thereby increase their chances of loneliness. On the other hand, the experiences of being lonely for a long 


\section{Personality Traits and the Feeling of Loneliness of Post-Graduate University Students}

time may lead a person to see him or herself as a social failure and so cause a drop in the person's self-esteem.

Upmanyu, Upmanyu and Dhingra (1992) studied loneliness among adolescents in relation to personality and cognitive measures. Loneliness correlated positively and significantly with hopelessness and negatively with locus of control and extraversion. The relationship revealed that male adolescents with internal locus of control, less social contact and higher amount of hopelessness were significantly more lonely. In another study, Jayakumari and Kalanidhi (1993) found a significant positive relationship between loneliness and neuroses in institutionalised and non-institutionalised aged by using UCLA Loneliness Scale. Cheng and Furnam (2002), in their study, found that psychoticism was a direct predictor of loneliness. In a study, Xueqing (2008) examined 281 female impoverished and 145 non-impoverished students. Correlative analysis showed significant negative correlation between extraversion and loneliness, while a significant positive correlation between psychoticism, neuroticism and loneliness.

Atak (2009) examined the association between the Big Five personality traits, and loneliness among Turkish emerging adults. A total of 220 emerging adults completed the NEO Five Factor Inventory (NEO-FFI), and the UCLA Loneliness Scale (UCLALS). Correlation analysis showed that three Big Five personality dimensions which are neuroticism (positively), and extraversion and agreeableness (negatively) are moderately correlated with emerging adults' loneliness. Regression analysis shows that extraversion, agreeableness and neuroticism are the most important predictors of emerging adults’ loneliness.

In another research conducted by Nayyar and Singh (2011) the relationship of loneliness with some important personality dimensions of young adults was investigated. For this purpose, a sample of 100 students, 50 males and 50 females with mean age 22.2 years and SD 0.66 , were administered revised UCLA - Loneliness Scale. 60 students (30 males and 30 females) who had a high score on loneliness were further assessed on the measures of Eysenck's Personality Questionnaire (Revised), Rotter's internal-External Scale, and IPAT- Anxiety Scale Questionnaire. It was broadly conjectured that there would be significant relationships between loneliness and extraversion, neuroticism, anxiety and locus of control. Data was processed using correlational analysis. The results obtained provided support to the hypotheses proposed in the study.

Thus, the review of literature shows that there are quite a few studies available which explore the relationship between loneliness and personality traits. But loneliness in young adulthood has not been studied extensively. There are only a few studies which investigate the relationship between emerging adults’ loneliness and personality traits. 


\section{RATIONALE OF THE STUDY}

There have been changing trends in the transition to adulthood and roles of individuals, especially during adulthood. Though the period of young adulthood may vary across various cultural groups, it is generally regarded as the period of instability. This is the time when young people become less dependent on their parents and become gradually an adult. These developmental tasks may bring "loneliness" which is very influential in the life of the emerging adults. This particular study was thus conducted keeping this in mind in order to gain a better understanding of loneliness and its relationship with personality traits so as to help the society from being its victim. As a result, the present study modestly looks in to the relationship of postgraduate university students’ feeling of loneliness with personality traits.

On the basis of theoretical analysis and relevant review of literature, the following objectives and hypotheses were formulated:

\section{OBJECTIVES}

O1: To assess the relationship of loneliness with neuroticism among post-graduate university students.

O2: To assess the relationship of loneliness with extraversion among post-graduate university students.

O3: To assess the relationship of loneliness with openness among post-graduate university students.

O4: To assess the relationship of loneliness with agreeableness among post-graduate university students.

O5: To assess the relationship of loneliness with conscientiousness among post-graduate university students.

O6: To assess gender differences among male and female post-graduate university students on variables of loneliness, neuroticism, extraversion, openness, agreeableness and conscientiousness.

\section{Hypotheses}

H1: There will be a positive relationship of loneliness with neuroticism among post-graduate university students.

H2: There will be a negative relationship of loneliness with extraversion among post-graduate university students.

H3: There will be a negative relationship of loneliness with openness among post-graduate university students.

H4: There will be a negative relationship of loneliness with agreeableness among post-graduate university students.

H5: There will be a negative relationship of loneliness with conscientiousness among postgraduate university students.

H6: There will be significant differences among male and female post-graduate university students on variable loneliness, neuroticism, extraversion, openness, agreeableness and conscientiousness. 


\section{METHOD}

It is necessary to adopt a systematic procedure to collect the necessary data which helps to test the hypotheses of the study. Various steps of research methodology to be followed in the present study are as follows:

\section{Sample}

A non-clinical sample of 60 post-graduate students (30 male and 30 female) from various disciplines in the age group of 21 to 24 years residing in Sikkim University hostels participated in this study. The mean age of the group was 22.6 with a SD of 0.68 . Student participation was voluntary, and none received compensation for taking part in the study. The selected subjects were required to be (a) showing no evidence of acute confused state, brain damage, alcoholism, or substance abuse, and (b) not currently in treatment for a diagnosed psychiatric disorder. The participants were contacted individually and were assured of anonymity and confidentiality.

\section{Tools Used}

The following psychological tools were used for the purpose of collection of data:

1. NEO Five-Factor Inventory-3 (Costa and McCrae, 1992):The NEO Five-Factor Inventory-3 (NEO-FFI-3)is the updated version of the NEO-FFI - a 60-item version of the NEO-PI-3. It provides a quick, reliable, and accurate measure of the five domains of personality and is particularly useful when time is limited and when global information on personality is needed. The NEO Inventories are concise measures of the five major dimensions, or domains, of personality - Neuroticism, Extraversion, Openness, Agreeableness and Conscientiousness and the most important traits or facets that define each domain. Together, the five broad domain scales and the 30 specific facet scales allow a comprehensive assessment of adolescents and adult personality. The NEO-FFI was designed by Costa and McCrae (1992) which contains 60 items to provide self and other reported measures of the five factor model of personality. Neuroticism (N), Extraversion (E), Openness (O), Agreeableness (A), and Conscientiousness (C) are the personality dimensions measured by the test. The NEO-FFI was developed from factor-analytic work on data from a 1986 administration of NEO-PI to 986 men and women. The NEO-FFI scales showed correlation ranging from .75 for conscientiousness to .89 for $\mathrm{N}$ when correlated with the NEO-PI, internal consistency for the NEO-FFI was calculated using alpha coefficient values were .89, .79, .74, and, .84 for N,E,O,A and C respectively. The validity of the NEO-FFI scales was tested by correlating the scales of the NEO-FFI to other measures of the five-factor model based on self-report, rating by spouses, and by peer rating of the NEO-PI factors. On selfreports, the convergent correlations ranged from .56 to .62, divergent correlation ranged from $\mathrm{p}$.

2. Perceived Loneliness Scale (Jha, 1997):The Perceived Loneliness Scale by Praveen Kumar Jha (1997)is a unidimensional self-report research tool which gives a holistic estimate of an individual. The scale consists of 36 items, among those 8 are negative items and 28 are positive items. The items were to be rated on five-point scale ranging from 1 (totally agree) 
to 5 (totally disagree). High score (5) reveals high loneliness and low score (1) reveals low loneliness of the respondents. An individual can score a maximum score of 180 and a minimum score of 36. The design of statement and the scoring pattern in such that the low score of an individual is indicative of low perceived loneliness whereas high score is to be interoperated as high perceived loneliness. The loneliness scale possesses fairly high reliability. Firstly, it was determined by Kudar-Richardson formula and the obtained value was to be.65 on a sample of 100 undergraduate students. Test-retest reliabilities were determined, one after an interval of 5 weeks and other of 8 weeks on a sample of 60 students. The values of these reliabilities were found to be. 84 and.82 respectively. The validity of the scale was examined by three ways, i.e., content validity, predictive validity and concurrent validity. It has been confirmed that the scale possess all three validity on which was examined.

\section{Procedure}

The tests were distributed among sixty first and second year Sikkim University male and female post-graduate students of science and arts faculty. The consent was obtained from the respondents and they were explained the purpose of the research as well as the details such as the instruction of the scale used. Sincere efforts were made to establish rapport with the respondents before the research was conducted for the purpose of eliciting reliable and authentic information. After taking their permission and consent, data were collected individually from the concerned respondents and the time taken by each respondent was twenty-five to thirty minutes. They were assured that information to be collected would remain strictly confidential and presented only in a form in which no person could be identified.

\section{RESULTS AND DISCUSSION}

One of the major objectives of the present study was to find out personality correlates of loneliness among post-graduate students of Sikkim University. Mean, SD and Pearson's correlation for loneliness, neuroticism, extraversion, openness, agreeableness and conscientiousness of post-graduate university students have been calculated by using Statistical Package for the Social Sciences (SPSS) version 22.0. In order to examine the gender differences of post-graduate university students on loneliness, neuroticism, extraversion, openness, agreeableness and conscientiousness, t- values have also been calculated. 
Table 1: Showing Mean, SD and Correlation for Loneliness, Neuroticism, Extraversion, Openness, Agreeableness and Conscientiousness among Post-graduate University Students $(N=60)$

\begin{tabular}{|l|l|l|l|l|l|l|l|l|}
\hline Variable & Mean & SD & L & N & E & O & A & C \\
\hline Loneliness (L) & 106.28 & 17.97 & 1.00 & -0.01 & -0.10 & $-0.24^{*}$ & $-0.24^{*}$ & $-0.24^{*}$ \\
\hline Neuroticism (N) & 27.82 & 14.25 & & 1.00 & $0.72^{*}$ & $0.70^{*}$ & $0.74^{*}$ & $0.41^{*}$ \\
\hline Extraversion (E) & 29.35 & 16.02 & & & 1.00 & $0.90^{*}$ & $0.72^{*}$ & $0.52^{*}$ \\
\hline Openness (O) & 29.65 & 14.23 & & & & 1.00 & $0.70^{*}$ & $0.50^{*}$ \\
\hline Agreeableness (A) & 26.3 & 8.16 & & & & & 1.00 & $0.57^{*}$ \\
\hline Conscientiousness (C) & 28.4 & 6.25 & & & & & & 1.00 \\
\hline
\end{tabular}

Note: $* P<0.05$

A careful observation of the correlation matrix from Table 1 reveals that loneliness is negatively and significantly correlated with openness $(-0.24)$. Therefore, hypothesis 3 states that "there will be a negative correlation of loneliness and openness among post-graduate university students” are accepted. People who are high on loneliness generally tend to be critical of new experiences and closed which is why people scoring low on openness tend to be high on loneliness variable.

Hypothesis 4 states that "there will be negative correlation of loneliness and agreeableness among post-graduate university students” and the results (Table 1)depict that loneliness is significantly and negatively correlated with agreeableness $(-0.24)$ thus proving the hypothesis 4 . Agreeable individual's value getting along with others. Agreeable people also have an optimistic view of human nature. Agreeable people are better liked than disagreeable people which is why agreeable people are generally less lonely since they have an optimistic view about others and thus loneliness is negatively correlated with agreeableness. The earlier findings by Atak (2009) also in line with the present result. He conducted a study which examines the association between the Big Five personality traits, and loneliness among Turkish emerging adults. Correlation analysis showed that three Big Five personality dimensions which are neuroticism (positively), and extraversion and agreeableness (negatively) are moderately correlated with emerging adults' loneliness. Regression analysis shows that extraversion, agreeableness and neuroticism are the most important predictors of emerging adults' loneliness.

Hypothesis 5 states that "there will be a negative relationship between loneliness and conscientiousness among post-graduate university students”. The hypothesis 5 is accepted as it can be observed from Table 1 that loneliness is negatively and significantly correlated with 
agreeableness (-0.24). Earlier study conducted by Kao (2012) also reports similar findings. Kao (2012) attempted to explore the relationship between personality traits, loneliness and university student's EFL Achievement. Loneliness was found to have significant negative relationships with three personality traits including extraversion, agreeableness and conscientiousness.

However, hypothesis 1 which states "there will be a positive relationship of loneliness with neuroticism among post-graduate university students” was not accepted. Similarly hypothesis 2 which states that "there will be a negative relationship of loneliness with extraversion among post-graduate university students” was also not accepted.

i. Table 2: Showing Mean, SD and t- Value of Male and Female Post-graduate University Students on Loneliness, Neuroticism, Extraversion, Openness, Agreeableness and Conscientiousness ( $N=60)$

\begin{tabular}{|c|c|c|c|c|c|c|c|}
\hline Sl.No. & Variables & Gender & $\mathbf{N}$ & Mean & SD & t- Value & $\begin{array}{l}\text { Sig/ } \\
\text { Not Sig }\end{array}$ \\
\hline \multirow[t]{2}{*}{1.} & \multirow[t]{2}{*}{ Loneliness } & Male & 30 & 105.67 & 10.14 & \multirow[t]{2}{*}{0.40} & \multirow[t]{2}{*}{ NS } \\
\hline & & Female & 30 & 106.90 & 23.52 & & \\
\hline \multirow[t]{2}{*}{2.} & \multirow[t]{2}{*}{ Neuroticism } & Male & 30 & 28.30 & 19.79 & \multirow[t]{2}{*}{0.40} & \multirow[t]{2}{*}{ NS } \\
\hline & & Female & 30 & 27.33 & 4.59 & & \\
\hline \multirow[t]{2}{*}{3.} & \multirow[t]{2}{*}{ Extraversion } & Male & 30 & 31.60 & 21.51 & \multirow[t]{2}{*}{0.14} & \multirow[t]{2}{*}{ NS } \\
\hline & & Female & 30 & 27.10 & 7.01 & & \\
\hline \multirow[t]{2}{*}{4.} & \multirow[t]{2}{*}{ Openness } & Male & 30 & 32.70 & 18.89 & \multirow[t]{2}{*}{0.06} & \multirow[t]{2}{*}{ NS } \\
\hline & & Female & 30 & 26.73 & 6.11 & & \\
\hline \multirow[t]{2}{*}{5.} & \multirow[t]{2}{*}{ Agreeableness } & Male & 30 & 26.93 & 10.49 & \multirow[t]{2}{*}{0.28} & \multirow[t]{2}{*}{ NS } \\
\hline & & Female & 30 & 25.67 & 4.94 & & \\
\hline \multirow[t]{2}{*}{6.} & \multirow[t]{2}{*}{ Conscientiousness } & Male & 30 & 28.07 & 6.74 & \multirow[t]{2}{*}{0.34} & \multirow[t]{2}{*}{ NS } \\
\hline & & Female & 30 & 28.73 & 5.82 & & \\
\hline
\end{tabular}




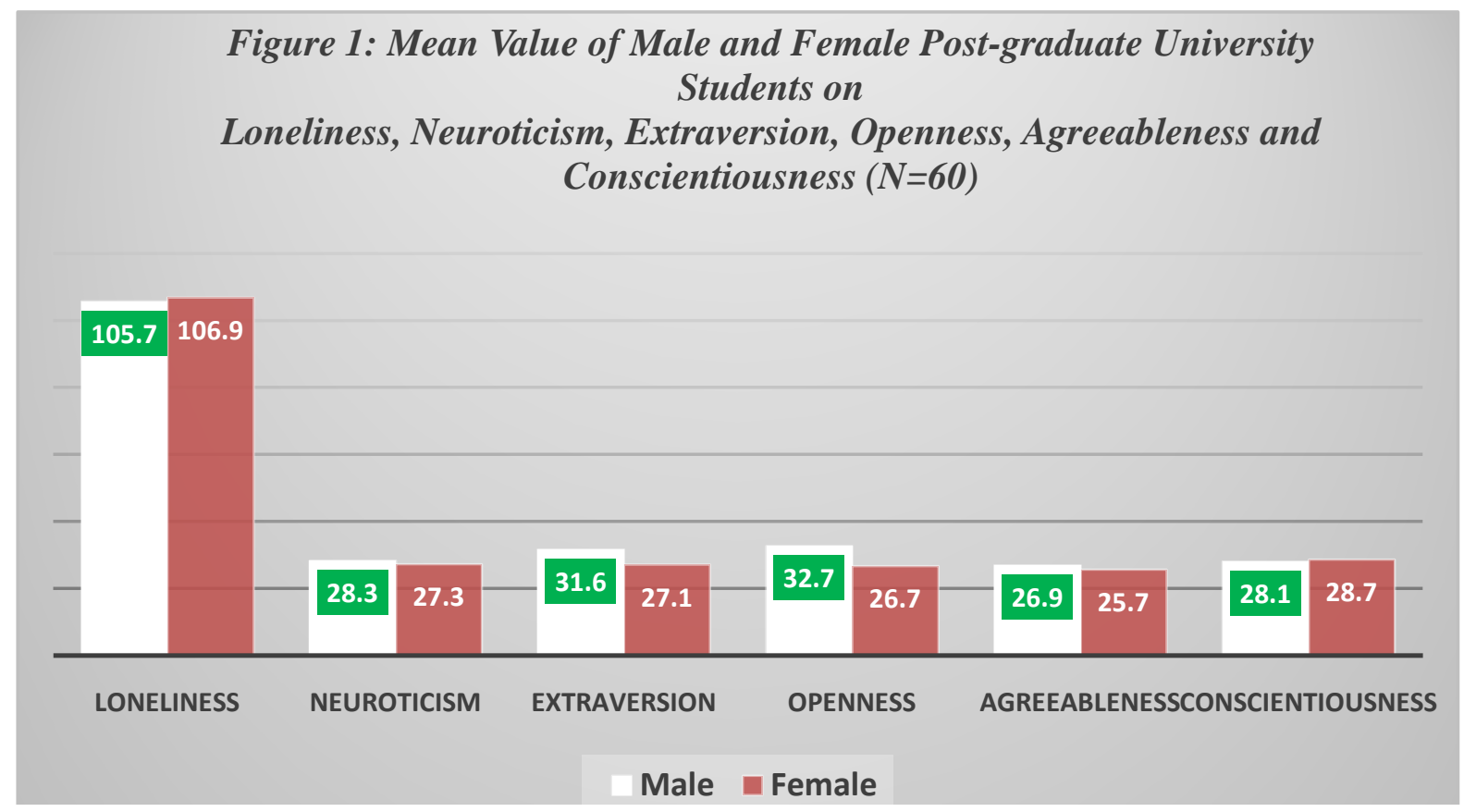

Table 2 shows Mean, SD and t-value of male and female post-graduate university students on neuroticism, extraversion, openness, agreeableness and conscientiousness. It can be observed that there was no significant difference between post-graduate males and females on neuroticism, extraversion, openness, agreeableness and conscientiousness. Figure 1 also shows the same trend. Therefore, hypothesis 6 which states that "there will be significant differences among male and female post-graduate university students on variable loneliness, neuroticism, extraversion, openness, agreeableness and conscientiousness" is not accepted. This could be because of the cultural value of the students which emphasizes on gender equality and there is no ascribed gender role as such for males and females.

\section{MAIN FINDINGS}

The main findings of the present study are as follows:

a. There existed negative correlation of loneliness and openness among post-graduate university students.

b. There was moderately negative correlation between loneliness and agreeableness among post-graduate university students.

c. There exists a negative relationship between loneliness and conscientiousness among postgraduate university students.

\section{CONCLUSION}

The present study was conducted keeping in mind the fact that young adults face a lot of academic pressure and so an understanding of loneliness in relation to personality was necessary in order to help society deal with various problems that were directly or indirectly associated with loneliness. Based on the present study, it can be concluded that the loneliness is negatively 
correlated to openness, agreeableness and conscientiousness of personality traits. Since high level of mean score of loneliness were found among post-graduate university students in this study, professionals need to pay attention to university students' psychosocial state. Because of the non-experimental and non-controlled design of this study, the generalizability of results may be limited.

\section{SUGGESTIONS FOR FURTHER RESEARCH}

The research studied personality correlates of loneliness only for young adults using a small sample. However, the research must be replicated using bigger samples so that the findings can be generalized. The present study focused on using post-graduate students from the same university. A comparative study is also possible between students from different universities by including more psychological variables. A cross-cultural study can also be done. In addition future research should also study loneliness using qualitative methods. Longitudinal research can be done to examine psychosocial factors among university students. In addition, further study is needed to investigate psychosocial interventions that decrease loneliness level and facilitate adaptation and socialization among university students.

\section{REFERENCES}

Arnett, J.J. (2007a). Emerging Adulthood: What Is It, and What Is It Good For? Child Development Perspectives. 1 (2), 68-73.

Atak, H. (2009). Big Five traits and loneliness among Turkish emerging adults. International Journal of Behavioral, Cognitive, Educational and Psychological Sciences, 1, 124-128.

Cheng, H. \& Furnham, A (2002). Personality, peer relations, and self-confidence as predictors of happiness and loneliness. Journal of Adolescence, 25(3), 327-339.

Costa, P. T. Jr., \& McCrae, R. R. (1992). NEO PI-R professional manual. Odessa, FL: Psychological Assessment Resources, Inc.

Jayakumari, G. \&Kalanidhi, M.S. (1993). Loneliness in relation to neuroses among the institutionalised and non-institutionalised elderly. Journal of Psychological Researches, 37(1\&2), 52-56.

Jha, P.K. (1997). Manual for Perceived Loneliness Scale (L-Scale). National Psychological Corporation: Agra.

Jones, W. (1982). Loneliness and social behaviour. In Peplau, A. \& Perlman, D. (eds.). Loneliness: A Sourcebook of Current Theory, Research and Therapy. (pp.238-254). NY: John Wiley and Sons.

Jones, W.H., Carpenter, B.N., \& Quitana, D. (1985). Personality and interpersonal predictors of loneliness in two cultures. Journal of Personality and Social Psychology, 48(6), 1503 1511.

Jones, W.H., Hansson, R., \& Smith, T.G. (1980). Loneliness and love: Implications for psychological and interpersonal functioning. As cited in Baron, A. And Byrne, D. (Eds.) Social Psychology, understanding human interaction, P. 524. 
Jones, W.H.; Briggs, S.R., \& Smith, T. G. (1986) Shyness: Conceptualization and measurement. Journal of Personality and Social Psychology, 51 (3), 629-633.

Kao, P. (2012). Exploring Personality Traits and Loneliness in University EFL (English as a Foreign Language) Learners. New Educational Review, 30 (4), 236.

Medora, N. \& Woodward, J.C. (1986). Loneliness among adolescent college students at a Midwestern university. Adolescence, 21(82), 391-402.

Nayyar, S. \& Singh, B. (2011). Personality correlates of loneliness. Journal of the Indian Academy of Applied Psychology, 37 (1), 163-168.

Peplau, L.A. \& Perlman, D. (1982). Perspectives on loneliness. In L.A. Peplau \& D. Perlman (Eds.), Loneliness: A sourcebook of current theory, research and therapy (pp. 1-18). New York: John Wiley.

Upmanyu, V. V., Upmanyu, S., \& Dhingra, M. (1992). Gender differences in loneliness. Journal of Personality and Clinical Studies, 8, 161-166.

Weiss, R. S. (1973). Loneliness: The experience of emotional and social isolation. Cambridge, MA: MIT Press.

Xuequing, TAN (2008). Characteristics of loneliness and its relationship with personality and social support in female impoverished students. Chinese Journal of Special Education, 11. 